\title{
A ANTROPOLOGIA AINDA PRECISA DE MUSEUS?
}

\author{
Nélia Dias' \\ Instituto Universitário de Lisboa
}

\section{RESUMO:}

O presente artigo busca mapear a relação entre a antropologia e o museu por meio de uma cartografia individual orientada pela pesquisa e pelo ensino na área de Museologia em Portugal. Alguns questionamentos são elencados para compreender, entre outras coisas, se um museu de antropologia é sinônimo de uma museologia antropológica. Nesta trajetória abriram-se pesquisas em diferentes museus como: Musée du quai Branly e o Musée de l'Homme na França. Pesquisas que visaram analisar as implicações epistemológicas do saber antropológico preconizado pelas instituições.

PALAVRAS-CHAVE:

Museu.Antropologia. Coleções.

\begin{abstract}
:
This article seeks to map the relationship between anthropology and the museum through a mapping guided through individual research and teaching in the field of Museology in Portugal. Some questions are given to understand, among other things, the anthropology museum is synonymous with an anthropological Museology. In this particular story, investigations were opened in different museums such as Musée du quai Branly and the Musée de l'Homme in France. Reserch that aimed to examine the epistemological implications of anthropological knowledge advocated by institutions.
\end{abstract}

\section{KEY-WORDS:}

Museum.Antropology. Collections. 
Em 200 I num livro editado por Mary Bouquet, Academic Anthropology and the Museum. Back to the Future, escrevi um texto, a pedido da coordenadora do volume, sobre as relações entre a minha experiência de ensino da museologia e a investigação antropológica em Portugal (DIAS, $200 \mathrm{la}$ ). $\mathrm{Na}$ altura não achei que o tema tratado pudesse ter relevância para os leitores, visto remeter apenas para a minha situação pessoal que não era, de forma alguma, ilustrativa do meio académico português. Dez anos mais tarde, Margaret Lopes pediu-me para dar conta da minha actividade docente no âmbito da museologia e da pesquisa desenvolvida em relação aos museus. E tal como em $200 \mathrm{I}$, as minhas reticências mantém-se ; se no início dos anos 2000 assistia-se ainda ao boom da museologia e a um certo entusiasmo pelos museus por parte dos alunos, actualmente a museologia não ocupa em Portugal um papel central tanto em termos académicos - cadeiras de opção nas licenciaturas e mestrados na área como no que diz respeito às publicações e investigação neste domínio.A dimensão pioneira e original que os museum studies ${ }^{2}$ deram para a abordagem dos museus suscitando um estímulo intelectual acabou por dar lugar a uma certa acalmia, que se traduz de uma certa forma, em abordagens mais convencionais e menos criticas em relação às práticas e aos fundamentos da museologia. Esta mudança de orientação parece-me ser sintomática da ausência de um paradigma novo na museologia ; mais ainda, com a crise económica que se instalou em Portugal e suas repercussões em termos do ensino superior e nomeadamente da procura por parte dos alunos, parece-me que a situação apresenta todas as condições para se manter.

\section{Ensino: da museologia etnográfica aos museus e colecções}

Desde dos anos 1990 que comecei a leccionar a Unidade curricular 'Museologia etnográfica', funcionando como optativa para os alunos de antropologia do $2^{\circ}$ e $3^{\circ}$ anos da licenciatura em Antropologia do ISCTE /IUL e também de outras áreas disciplinares, nomeadamente da licenciatura em História moderna e contemporânea. Em 2008 esta unidade curricular alterou a sua designação passando a ser intitulada 'Museus e Colecções', numa clara tentativa de alargar o seu conteúdo programático e de abordar o leque mais vasto de museus. Foi minha a decisão de alargar o conteúdo desta unidade curricular porque considerei por um lado, que a museologia etnográfica tinha deixado de ser, em termos de publicações recentes, um domínio em crescimento e que, pelo contrário, assistíamos cada vez mais a publicações de âmbito geral, da esfera dos museum studies ${ }^{3}$. Por outro lado, que a relação entre o ensino da museologia nos departamentos de antropologia e os museus etnográficos, nomeadamente - Museu de Etnologia (Lisboa) longe de se fortalecer, estava, bem pelo contrário, a esvanecer e que o fosso entre as duas esferas só poderia ser cada vez maior. Muitas vezes a primeira (e única) visita a este museu por parte dos alunos ocorre no âmbito do $I^{\circ}$ ano da licenciatura.

A designação Museum anthropology revela, de uma certa maneira, a ambiguidade do relacionamento entre estas duas esferas. $O$ museum anthropology é sinónimo de museologia antropológica ou de antropologia dos museus? Como sublinhou Kaplan (1996, p. 813) "museum anthropology may be defined either as anthropology practiced in museums or as the anthropology of museums". Esta

2 É sintomático que os Museum Studies tenham-se tornado, a partir dos anos 2000, num objecto de estudo.Ver: Starn ( 2005) e Macdonald ( 2006).

3 Ver: MacDonald (2006). 
ambiguidade é reveladora do mal estar entre a antropologia e os museus e se, tal é a minha hipótese, os antropólogos souberam encontrar no museu um novo e rico objecto de investigação, os museus por seu lado não conseguiram ainda captar através de temáticas e domínios de investigação a atenção dos antropólogos.

Apesar da unidade curricular 'Museus e Colecções' ter uma grande procura por parte dos alunos, no entanto saber até que ponto esta unidade curricular tem o seu lugar numa licenciatura de antropologia, é uma questão em aberto. Apesar da existência no currículo da licenciatura de antropologia de outras unidades curriculares com afinidades com a museologia, tais como 'Análise de objectos' e 'Antropologia da arte', no entanto elas não constituem um conjunto sistematizado em termos de conteúdos programáticos e articulação curricular, cabendo aos discentes efectuar as articulações necessárias.

Paralelamente ao ensino ao nível da licenciatura, tenho leccionado também desde há mais de 15 anos a unidade curricular 'Questões de Museologia' ao nível do Mestrado em Museologia - Conteúdos Expositivos, mestrado organizado em conjunto com o departamento de História moderna e contemporânea e o departamento de Antropologia.

A unidade curricular, 'Questões de museologia', funciona como cadeira obrigatória para os alunos do $1^{\circ}$ ano do mestrado mas também para aqueles que, depois de uma pós-graduação, obtiveram equivalências e ingressam directamente no $2^{\circ}$ ano do mestrado. Como o titulo deixa claro, trata-se de uma unidade curricular com um conteúdo muito geral ; a primeira parte do programa é dedicada à emergência e consolidação dos museus nas suas relações com campos disciplinares, a segunda parte focando questões de actualidade tais como a arquitectura dos museus, a importância dos museus na indústria cultural e na indústria do turismo, as relações entre museus e memoriais.

As temáticas das dissertações de mestrado e de doutoramento que orientei prendem-se com os percursos e os interesses profissionais dos discentes. Assim algumas dissertações incidiram sobre projectos de renovação de salas de museus e de palácios nacionais, a incorporação e a desincorporação nos museus portugueses, a introdução de novas tecnologias, os museus virtuais, o processo de digitalização das colecções públicas portuguesas e o programa Matrix, as colecções recolhidas pelos missionários da Congregação de Espírito Santo em Angola nos inícios do século 20 e actualmente conservadas no Museu antropológico de Coimbra.

Depois de ter suscitado uma imensa procura por parte dos estudantes, - Mestrado em Museologia - Conteúdos expositivos tem vindo a perder a sua atractividade inicial, provavelmente por necessitar de uma reformulação a nível dos conteúdos programáticos. Se atendermos ao facto de outros mestrados e cursos de pós-graduação em museologia existentes em Portugal continuarem a atrair numerosos estudantes, talvez o verdadeiro problema não resida na diminuição da procura mas sim numa oferta diversificada e consequente competição entre instituições universitárias.

Convém salientar que, pela primeira vez em Portugal, foi estabelecido em 2010 um protocolo de colaboração entre o Instituto dos Museus e da Conservação (IPM) através do seu director, Professor Doutor João Brigola, e a Fundação para a Ciência e a Tecnologia (FCT) visando 'a necessidade de reforço e criação de investigação centrada nos Museus portugueses e suas colecções'. A luz deste protocolo, foi aberta uma nova área temática no concurso geral de atribuição de Bolsas de doutoramento e pós-doutoramento da FCT, sob a designação 'Museologia, Conservação e Restauro', com particular incidência em torno da história 
das colecções e museus. Para além do orientador, pertencente a uma instituição do Ensino Superior, os candidatos deviam ter um co-orientador pertencente à unidade museológica na qual seria desenvolvido o trabalho de investigação.

Tendo tido o privilégio de coordenar o painel 'Museologia, Conservação e Restauro', pude assim obter um panorama geral de quais as áreas de pesquisa em curso, quais as temáticas mais procuradas pelos estudantes e aquelas que suscitam um certo desinteresse. Esta experiência permitiu-me constatar a relativa ausência de pesquisas em torno da história das colecções / museus e da figura do coleccionador como temas de investigação. Seria interessante reflectir sobre as razões pelas quais a história das colecções e dos museus tem vindo a ser negligenciada pelos académicos e consequentemente pelos futuros académicos, alunos de mestrado e de doutoramento.

\section{Do Musée du quai Branly às práticas de coleccionar}

Tendo iniciado a minha pesquisa com o estudo da fundação em 1878 do primeiro museu etnográfico em Paris, o Musée d'Ethnographie du Trocadéro (DIAS, 199I), achei que era uma ocasião única poder analisar o processo de criação de um novo museu, o Musée du quai Branly, no século $X X I$, reunindo as colecções de etnologia do Musée de l'Homme e as do Musée National des Arts d'Afrique et d'Océanie. $O$ meu objectivo inicial era o de fazer uma etnografia do projecto museológico, tentando perceber quais as escolhas museográficas, assistir às reuniões de trabalho entre etnólogos, museografos e conservadores, perceber quais os critérios de selecção dos objectos bem como as articulações entre a museografia e o projecto arquitectónico. Considerei que fazer uma etnografia de um projecto museológico, tendo como referência os trabalhos de Macdonald (2002) no Science Museum (Londres) poderia ser um exercício altamente estimulante. Como Thomas (2010, p. I4) sublinhou recentemente:

While the former narrow, almost automatic connection between anthropology and the ethnographic museum no longer seems to work, the ethnographic approach seems patently well-suited for analysing other kinds of museum.

Proceder a uma etnografia de um museu etnográfico em construção levantou um certo número de obstáculos, pelo que fui levada a pôr de lado o projecto inicial e a focalizar apenas na documentação secundária (sob forma de artigos nos jornais europeus e norte-americanos e artigos dos principais protagonistas deste museu publicados em revistas especializadas).

O meu primeiro texto sobre o Musée du quai Branly publicado em 200 I foi uma espécie de descrição das diversas etapas institucionais, das medidas legislativas, seguida de uma contextualização dos debates em curso. Paralelamente redigi outros artigos sobre a criação em 2000 da antena no Louvre, o Pavillon des Sessions, contendo mais de 100 obras primas de arte não ocidental (DIAS, 2002) e sobre as designações à volta do futuro museu, nomeadamente a utilização, durante os anos 2002-2004, do termo 'arts premiers' (DIAS, 2003). Tentei também analisar as implicações epistemológicas subjacentes ao Musée du quai Branly, tais como : que tipo de saber antropológico era dado a ver, qual o conteúdo da diversidade cultural preconizado por esta instituição e qual a mensagem politica veiculada (DIAS 2006; 2008a). Posteriormente e no seguimento da abertura deste museu ao público em 2006, tentei examinar qual o papel do passado histórico das colecções no seio desta instituição (DIAS, 2008b) e retra- 
çar as rupturas bem como as continuidades entre o primeiro museu etnográfico (I878) e o Musée du quai Branly (DIAS, 2007b). Abandonei provisoriamente a análise do Musée du quai Branly, análise essa que focou apenas e exclusivamente sobre as colecções permanentes, visto que, nos últimos anos, numerosos artigos e livros foram publicados em torno desta instituição.

Paralelamente, retomei desde 2009 dois temas que tinha brevemente sido abordado há mais de 20 anos, nomeadamente as colecções de crânios e os troféus de caça. Graças ao amável convite de Irina Podgorny et Francesco de Ceglia para participar no workshop 'Immortal Bodies' organizado pelo Max Planck Institute for the History of Science ( Berlin) em Janeiro de 20I I, tive a oportunidade de re-trabalhar os materiais relativos ás practicas de recolha de crânios no século 19, tentando perceber as lógicas epistemológicas subjacentes a este tipo de colecções (artigo no prelo para Nuncius). Um tipo de abordagem semelhante presidiu ao texto que redigi sobre a colecção de troféus de caça do Duc d'Orleans, colecção que deu origem nos anos 1930 ao Musée du duc d'Orléans dependente do Muséum national d'Histoire naturelle (Paris). De uma certa maneira, estes dois temas estão estreitamente ligados se atendermos aos facto que alguns crânios humanos (sobretudo de inimigos capturados durante expedições militares) foram trazidos para Europa como troféus.

Desde dos inícios de $201 \mathrm{I}$, integrei um projecto de pesquisa coordenado por Tony Bennett financiado pelo Australian Research Council (ARC); este projecto que tem a duração de três anos, intitulado 'Museum, Field, and Colony. Practices of Social Governance' reúne cinco outros investigadores, entre os quais Ira Jacknis, Rodney Harrison, Conal McCarthy, Ben Dibley e Fiona Cameron. O projecto tem por objectivo elaborar um estudo sistemático e comparativo das práticas de recolha de objectos entre os finais do século 19 e os princípios do século 20 em cinco contextos nacionais (França, EUA, Austrália, Nova Zelândia e Gra-Bretanha) ; a diversidade destes contextos nacionais estando associada a práticas de governação distintas. Centrada em torno dos museus etnográficos em França, a minha participação no projecto visa explorar os preceitos metodológicos e epistemológicos subjacentes á recolha de objectos no terreno levada a cabo pelos etnólogos franceses durante a primeira metade do século 20 O trabalho de campo implicou um novo tipo de relações entre os museus e o terreno, nomeadamente os terrenos coloniais, encarados como centros de recolha. Paralelamente, pretendo examinar a maneira como o Musée de l'Homme funcionou como uma espécie de Grand Central, um ponto central no seio de uma rede de instituições espalhadas tanto no território francês como nas antigas colónias. Esta instituição reuniu quase todas as colecções espalhadas em Paris, não apenas as colecções de etnografia, como também as de antropologia física e de arqueologia. Por outro lado, o Musée de l'Homme funcionou como um centro de coordenação de uma vasta rede de museus espalhados nas diferentes partes do mundo, sobretudo nas antigas colónias francesas mas também em países da América Latina, como o Equador. Deste ponto de vista, este museu desempenhou um papel de centro de cálculo, segundo a expressão de Bruno Latour, como lugar onde objectos e informação provenientes de várias partes do mundo foram reunidos, sistematizados e transformados em materiais científicos.

Um dos meus propósitos é o de questionar a pertinência da noção de centro de cálculo. No caso francês, se o Musée de l'Homme funcionou até um certo ponto como um centro de cálculo, contudo a existência de museus nas diversas colónias francesas de Africa ocidental e na Indochina bem como a hierarquia entre os vários museus nas colónias, permite atenuar um pouco 
a concepção de um único centro de cálculo. Por exemplo, o museu de Dakar serviu de centro de cálculo em relação aos outros museus da chamada Africa Ocidental francesa e o museu de Hanoi desempenhou um papel semelhante em relação aos outros museus do Extremo Oriente.

No primeiro ano do projecto, a tónica será posta na analise das relações entre museus metropolitanos e museus nas colónias, a circulação de informação, de objectos e de pessoas entre estes dois tipos de instituição e as suas articulações com práticas especificas de governamentalidade, e nomeadamente as práticas de administração colonial.

O estudo das colecções antropológicas do século 19 até aos dias de hoje permitiu-me corroborar o ponto de vista de Thomas (2010, p. 8), segundo o qual "Anthropological collections are always also historical collections; they are the products of, the evidence of, and maybe even the memorials to entangled histories". Esta perspectiva esteve de uma certa forma presente aquando o debate ocorrido entre 2006 e 2009 em torno do destino a dar ao Museu de Arte popular (Lisboa). A mobilização de uma parte da comunidade antropológica portuguesa e as controvérsias entre apologistas de conservação do museu enquanto 'museu de si próprio' versus defensores da transformação deste museu e consequente abertura a outras formas de cultura popular ${ }^{4}$ revelaram a importância da disciplina antropológica nos debates culturais contemporâneos. Maioritariamente centrada nos museus que possuem colecções etnográficas nacionais (ver Leal no prelo), a produção antropológica em Portugal tem vindo a orientar-se para as questões do património cultural imaterial, como testemunha a publicação recente por parte do Instituto dos Museus e da Conservação (MUSEU..., 2009).

\section{Referências}

DIAS, N. Le Musée d'ethnographie du trocadero (I878-1908):anthropologie et museologie en France. Paris: Editions du CNRS, 1991.

DIAS, N.'Does anthropology need museums?': teaching ethnograhic museology in Portugal, thirty years later. In: BOUQUET, M. (Ed.). Academic anthropology and the museum. New York: Berghahn Books, 200 la. p. 92- 105.

DIAS, N. Esquisse ethnographique d'un projet: le musée du Quai Branly. French Politics, Culture \& Society, v. 19, n. 2, p. 8I-I0I, $200 \mathrm{Ib}$.

DIAS, N. Une place au Louvre. In: GONSETH M. O.; HAINARD,J. (Ed.). Le musee cannibale. Neuchâtel: Musée d'Ethnographie de Neuchâtel, 2002. p. I5-29.

DIAS, N. Ethnographie, art, arts premiers: la question des désignations. Arquivos do Centro Cultural Calouste Gulbenkian, v. 45, p. 3-13, 2003.

DIAS, N.What's in a name?: anthropology, museums and values. In: GREWE G. (Ed.). Die Schau des Fremden. Ausstellungskonzepte zwischen Kunst, Kommerz und Wissenschaft. Stuttgart: Franz Sterner Verlag, 2006. p. 169- I 85.

DIAS, N. Des 'arts méconnus' aux 'arts premiers': inclusions et exclusions en anthropologie et en histoire de l'art. Histoire de l'Art, n. 60, p. 5-13, 2007a.

DIAS, N. Le musée du quai Branly: une généalogie. Le Débat, n. I47, p. 65-79, 2007 b. DIAS, N. Cultural difference and cultural diversity: the case of the musée du quai Branly. In: SHERMAN, D. J. (Ed.). Museums \& difference. Bloomington: Indiana University Press, 2008. p. I24-I54.

4 Ver Dossier Etnográfica (MUSEU..., 2009). 
DIAS, N. Double erasures: rewriting the past at the musée du quai Branly. Social Anthropology, v. 16, n. 3, p. I-12, 2008.

LEAL, J. O povo no museu. Museologia.pt. (No prelo).

KAPLAN, F. Museum anthropology. In: LEVINSON, D.; EMBER, M. (Ed.). Encyclopaedia of cultural anthropology. New York: Henry Holt and Co, 1996. p. 8I 3-8I 7. MACDONALD, S. Behind the scenes at the science museum. Oxford:Berg, 2002. MACDONALD, S. Review article: reviewing museum studies in the age of the reader. Museum and Society, v. 4, n. 3, p. I66-172, 2006.

MUSEU de arte popular: extinguir, metamusealizar, redinamizar? Etnográfica, v. I3, n. 2, p. 465-480, 2009.

MUSEU e património imaterial: agentes, fronteiras, identidades. Lisboa: Instituto dos Museus e da Conservação, 2009.

STARN, R. A historian's brief guide to the new museum studies. American Historical Review, p. 68-98, February 2005.

THOMAS, N.The museum as method. Museum Anthropology, v. 33, n. I, p. 6-10, 2010.

Artigo recebido em junho de 20/3. Aprovado em agosto de 2013 